\title{
Transcriptional repressor CopR acts by inhibiting RNA polymerase binding
}

Correspondence

Sabine Brantl

Sabine.Brantl@uni-jena.de

Received 13 December 2010

Revised 12 January 2011

Accepted 13 January 2011

\author{
Andreas Licht, $\uparrow$ Peggy Freedeł and Sabine Brantl
}

Friedrich-Schiller-Universität Jena, Biologisch-Pharmazeutische Fakultät, AG Bakteriengenetik, Philosophenweg 12, Jena D-07743, Germany

\begin{abstract}
CopR is a transcriptional repressor encoded by the broad-host-range streptococcal plasmid pIP501, which also replicates in Bacillus subtilis. It acts in concert with the antisense RNA, RNAIII, to control pIP501 replication. CopR represses transcription of the essential repR mRNA about 10- to 20-fold. In previous work, DNA binding and dimerization constants were determined and the motifs responsible localized. The $\mathrm{C}$ terminus of CopR was shown to be required for stability. Furthermore, SELEX of the copR operator revealed that in vivo evolution was for maximal binding affinity. Here, we elucidate the repression mechanism of CopR. Competition assays showed that CopR-operator complexes are 18-fold less stable than RNA polymerase (RNAP)-pll complexes. DNase I footprinting revealed that the binding sites for CopR and RNAP overlap. Gel-shift assays demonstrated that CopR and B. subtilis RNAP cannot bind simultaneously, but compete for binding at promoter pll. Due to its higher intracellular concentration CopR inhibits RNAP binding. Additionally, $\mathrm{KMnO}_{4}$ footprinting experiments indicated that prevention of open complex formation at pll does not further contribute to the repression effect of CopR.
\end{abstract}

\section{INTRODUCTION}

Replication of the streptococcal plasmid pIP501 is regulated by two components that act in concert: the transcriptional repressor CopR $(10.6 \mathrm{kDa})$ and the antisense RNA RNAIII (136 nt) (Brantl \& Behnke, 1992). Whereas RNAIII exerts its inhibitory effect by attenuation of the essential repR mRNA (Brantl et al., 1993; Brantl \& Wagner, 1994), CopR has a dual function: it represses transcription from the essential repR promoter $\mathrm{pII}$ about 10- to 20-fold (Brantl, 1994), and it prevents convergent transcription from pII and pIII (antisense promoter), thereby indirectly increasing transcription initiation at pIII (Brantl \& Wagner, 1997, Fig. 1). Previously, we found that CopR contacts the DNA asymmetrically at two consecutive major grooves that share the consensus motif $5^{\prime}$-CGTG and narrowed down the operator sequence to $17 \mathrm{bp}$ (Steinmetzer \& Brantl, 1997). Furthermore, we demonstrated that CopR binds exclusively as a dimer and calculated the equilibrium dissociation constants for the CopR dimers and the CopR-DNA complex to be $0.4 \mathrm{nM}$ and $1.4 \mu \mathrm{M}$, respectively (Steinmetzer et al., 1998). A 3D model of the N-terminal 63 amino acids of CopR was built,

†Present address: Jena Bioscience GmbH, Löbstedter Straße 80, 07749 Jena, Germany.

‡Present address: Koburger Str. 60, 51103 Köln, Germany.

Abbreviations: $\alpha \mathrm{CTD}, \mathrm{C}$-terminal domain of the $\alpha$ subunit of RNA polymerase; EMSA, electrophoretic mobility shift assay; PAA, polyacrylamide; RNAP, RNA polymerase; SELEX, systematic evolution of ligands by exponential enrichment (in vitro selection). allowing the identification of amino acids involved in DNA binding and dimerization (Steinmetzer et al., 2000a, b, 2002a). Furthermore, it was established that the structured acidic C terminus of CopR that forms a $\beta$-strand is necessary for stabilization of the protein (Kuhn et al., 2000, 2001). A fluorescence energy study revealed that CopR bends the operator DNA slightly - $20-25^{\circ}$ - upon binding (Steinmetzer et al., 2002b). A SELEX analysis showed that in vivo evolution of the $\operatorname{cop} R$ operator was directed at maximal binding efficiency (Freede \& Brantl, 2004). Plasmid pIP501 belongs, together with $\operatorname{pAM} \beta 1$ and pSM19035, to the Inc18 family of broad-host-range streptococcal plasmids (Brantl et al., 1990). These plasmids replicate via the theta mechanism in a broad range of Gram-positive hosts, among them Bacillus subtilis. The corresponding Cop proteins CopR, CopF (Swinfield et al., 1990) and CopS (Ceglowski et al., 1993) and their binding regions are highly homologous.

Initiation of transcription is a stepwise process (Rojo, 1999), starting with the binding of the RNA polymerase to the promoter and formation of a loose closed complex, which is subsequently rearranged into a tighter closed complex. This is followed by the melting of the DNA around the transcriptional start site, called the open complex. Afterwards, RNA polymerase (RNAP) can form the initiation complex and begin to transcribe the DNA, often producing short abortive transcripts resulting from failed attempts to leave the promoter. Eventually, RNAP escapes the promoter and forms the elongation complex. Virtually every one of these steps can be exploited for 


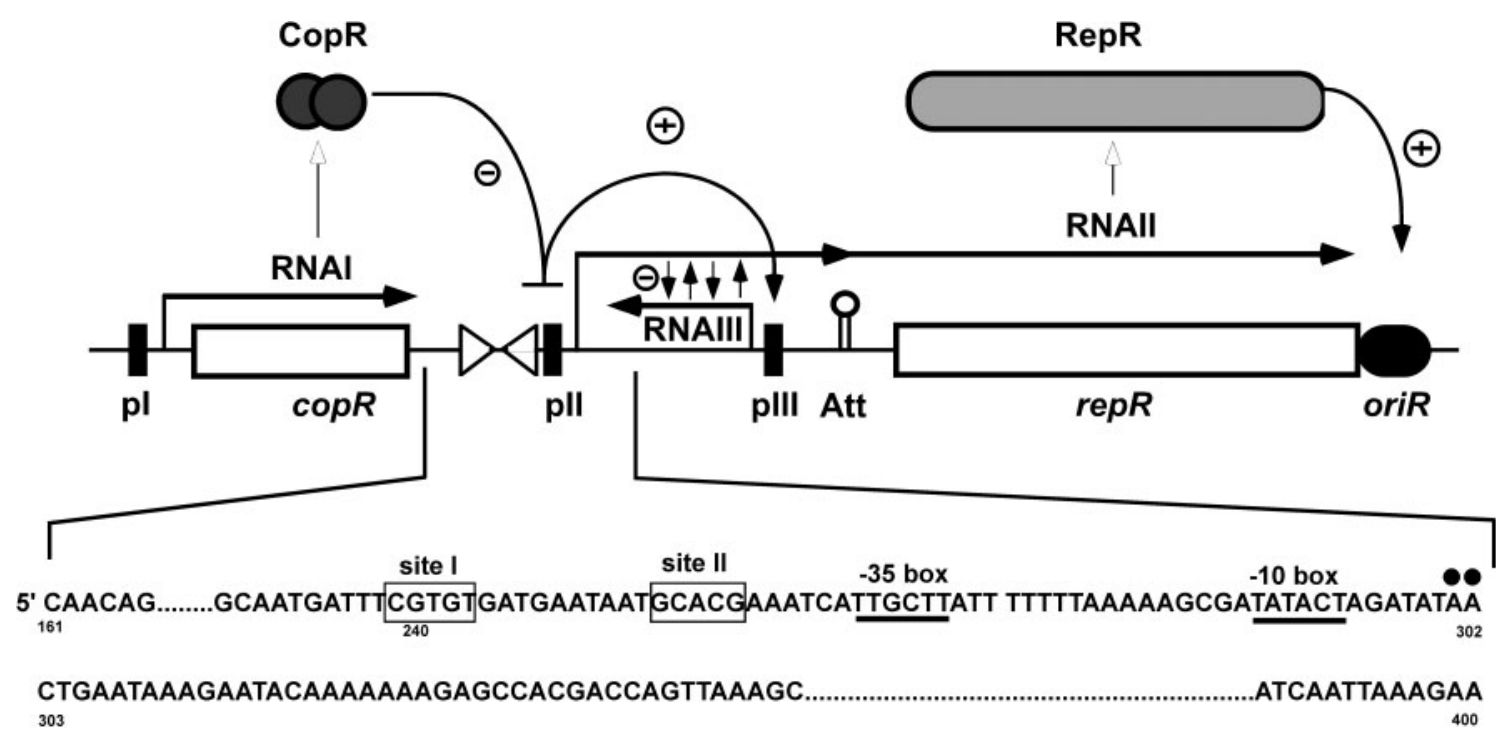

Fig. 1. Working model with CopR operator sequence. Upper part: working model of copy number control of plasmid pIP501 in B. subtilis. Black boxes, promoters; open rectangles, open reading frames; thick arrows, RNAs; grey boxes, proteins; oriR, replication origin; filled arrows, activation/positive interactions; horizontal bar, repression; Att, position of premature termination of RNAll transcription. The negative regulation by CopR is transcriptional and is exerted at the repR promoter pll. Negative regulation by RNAll is via induction of transcription termination of RNAll. Repressed RNAll transcription (presence of CopR) permits increased RNAlll transcription (Brantl \& Wagner, 1997). Lower part: schematic representation of the DNA sequence containing the CopR target. Minimal binding sites I and II are highlighted by boxes. The -35 and -10 regions of promoter pll are underlined. Dots indicate the transcription start points of RNAll. The fragment used for EMSA comprised nt 190-400, whereas the fragment used for DNase I footprinting and $\mathrm{KMnO}_{4}$ footprinting comprised nt 160-395. Nucleotide numbering is according to Brantl et al. (1990).

transcription repression (Rojo, 1999, 2001). For instance, Escherichia coli repressor Fur and Streptococcus pneumoniae repressor MalR act by steric hindrance of RNAP binding (Escolar et al., 1998; Nieto et al., 2001) whereas B. subtilis Spo0A and E. coli Arc inhibit open complex formation at the $a b r B$ and $\mathrm{p}_{\text {ANT }}$ promoters, respectively (Greene \& Spiegelman, 1996; Smith \& Sauer, 1996). By contrast, $B$. subtilis phage $\Phi 29$ protein $\mathrm{p} 4$ and architectural protein FIS prevent promoter escape at viral A2c and E. coli gyrB, respectively (Monsalve et al., 1996; Schneider et al., 1999). Recently, we demonstrated that one repressor employs different repression mechanisms at different promoters: $B$. subtilis $\mathrm{CcpN}$ represses abortive transcription at the gapB promoter, but promoter escape at the $s r 1$ and $p c k A$ promoters (Licht \& Brantl, 2009). Interestingly, plasmid pMV158-encoded repressor CopG uses two different mechanisms at the same promoter: it prevents RNAP binding and reverses open complex formation by dislodging RNAP from $\mathrm{P}_{\mathrm{cr}}$ (Hernández-Arriaga et al., 2009).

To clarify the repression mechanism exerted by CopR, we used electrophoretic mobility shift assays (EMSAs) with CopR and RNAP alone and in combination to analyse steric hindrance. Competition assays with unlabelled operator fragments were applied to calculate the half-lives of the CopR-pII and the RNAP-pII complexes to be $1.2 \mathrm{~min}$ and $22 \mathrm{~min}$, respectively. DNase I footprinting revealed that the binding regions of CopR and RNAP overlap partially. Furthermore, we performed chemical footprinting with $\mathrm{KMnO}_{4}$ to investigate a possible additional influence of CopR on open complex formation at pII. Taken together, our data show that CopR has only one activity: it inhibits RNAP binding to promoter pII.

\section{METHODS}

Enzymes and chemicals. A PCR kit from Roche was used for PCR amplifications. DNA sequencing was performed by the dideoxy chain-termination method with a Sequenase kit from Amersham Bioscience. Chemicals were of the highest available purity.

Overexpression and purification of $\mathbf{H i s}_{\mathbf{6}}$-CopR. Plasmid pQC60 used for overexpression and purification of a C-terminally $\mathrm{His}_{6}$ tagged CopR protein from E. coli was constructed by cloning of a $307 \mathrm{bp} \mathrm{NcoI/BglII}$ fragment generated by PCR on plasmid pCOP7 (Brantl \& Behnke, 1992) as template with primers SB299 (5'-GAA TTC CCA TGG AAC TAG CAT TTA GAG AA-3') and SB300 (5' CTG CAG AGA TCT TTA TTA GTG ATG GTG ATG GTG-3') into the NcoI/BglII-digested vector pQE60 (Qiagen). The sequence was confirmed. Purification of $\mathrm{His}_{6}$-CopR from E. coli TG1(pQC60) was performed as described previously (Steinmetzer et al., 1998). Cterminally $\mathrm{His}_{6}$-tagged CopR was verified to function in vivo (not shown).

Purification of $\mathbf{H i s}_{\mathbf{6}}$-RNA polymerase from B. subtilis. B. subtilis strain 168 containing an $r p o C$ gene with a $3^{\prime}$ terminal $\mathrm{His}_{6}$-tag was 
grown in $150 \mathrm{ml} \mathrm{LB}$ medium containing $50 \mu \mathrm{g}$ spectinomycin $\mathrm{ml}^{-1}$ at 175 r.p.m. at $37{ }^{\circ} \mathrm{C}$ to $\mathrm{OD}_{600} 2.0-3.0$. Cells were harvested by $5 \mathrm{~min}$ centrifugation at 8000 r.p.m. for $5 \mathrm{~min}$ at $4{ }^{\circ} \mathrm{C}$ and the pellet frozen overnight at $-20{ }^{\circ} \mathrm{C}$. Cells were resuspended in $10-15 \mathrm{ml}$ lysis buffer (50 mM sodium phosphate $\mathrm{pH} 8.0,300 \mathrm{mM} \mathrm{NaCl}$ containing $120 \mu \mathrm{l}$ PMSF added from a $0.1 \mathrm{M}$ stock solution), and sonicated on ice three times for $10 \mathrm{~min}$ each. Cell debris was pelleted at $4{ }^{\circ} \mathrm{C}$ for $10 \mathrm{~min}$ at 13000 r.p.m., and supernatant loaded onto a $\mathrm{Ni}^{2+}$-NTA agarose column (Qiagen) containing $0.5 \mathrm{ml}$ bed volume. The column was equilibrated with 2 vols lysis buffer. After collecting the flow-through, the column was washed twice with lysis buffer, followed by one elution step with $0.5 \mathrm{ml} 50 \mathrm{mM}$ sodium phosphate $\mathrm{pH} 8.0,300 \mathrm{mM}$ $\mathrm{NaCl}, 12.5 \mathrm{mM}$ imidazole, a second elution step with $0.5 \mathrm{ml} 50 \mathrm{mM}$ sodium phosphate $\mathrm{pH} 8.0,300 \mathrm{mM} \mathrm{NaCl}, 25 \mathrm{mM}$ imidazole, and a third elution step with $0.5 \mathrm{ml} 50 \mathrm{mM}$ sodium phosphate $\mathrm{pH} 8.0$, $300 \mathrm{mM} \mathrm{NaCl}, 37.5 \mathrm{mM}$ imidazole. Afterwards, the column was washed with $5 \mathrm{ml} 50 \mathrm{mM}$ sodium phosphate $\mathrm{pH} 8.0,300 \mathrm{mM} \mathrm{NaCl}$, $125 \mathrm{mM}$ imidazole. Glycerol was added to a final concentration of $50 \%$ to each elution fraction; fractions were stored at $-20{ }^{\circ} \mathrm{C}$ and analysed in a $12 \%$ SDS-PAA gel.

Preparation of the labelled CopR target. The $210 \mathrm{bp}$ CopR target for EMSAs was generated by a PCR with $\left[\gamma_{-}^{32}\right.$ P]ATP-labelled oligodeoxyribonucleotide SB1480 (5'-GTA ACA TTG GAG TTA GAA-3') and unlabelled oligodeoxyribonucleotide SB1481 (5' GTA TTC TTT ATT CAG TTC-3') on plasmid pPR1 (Brantl \& Behnke, 1992) as template.

EMSA. Binding reactions with $\mathrm{His}_{6}$-tagged CopR or RNAP were performed in a final volume of $20 \mu \mathrm{l}$ of binding buffer (BB) containing $100 \mathrm{mM}$ potassium glutamate, $10 \mathrm{mM}$ Tris/ $\mathrm{HCl} \mathrm{pH} 8.0$, $0.1 \mathrm{mM}$ EDTA, $50 \mathrm{mM} \mathrm{KCl}, 1 \mathrm{mM} \mathrm{CaCl}, 5 \mathrm{mM} \mathrm{MgCl}_{2}, 1 \mathrm{mM}$ DTT, $10 \mathrm{mg} \mathrm{BSA}^{-1}, 5 \%(\mathrm{v} / \mathrm{v})$ glycerol and $1 \mathrm{nM}$ end-labelled DNA fragment. This buffer, which allows only the formation of closed complexes, had to be used to ensure the visualization of both CopR and RNAP complexes with the pII promoter/operator region. Herring sperm DNA $\left(0.05 \mathrm{~g} \mathrm{l}^{-1}\right)$ was added as non-specific competitor. After incubation at $37^{\circ} \mathrm{C}$ for $30 \mathrm{~min}$, the reaction mixtures were separated on $5 \%$ native PAA gels run at room temperature at $230 \mathrm{~V}, 25 \mathrm{~mA}$ in $0.5 \times$ TBE buffer. Visualization and quantification of the bands were performed on a Fuji-PhosphorImager using the program PCBAS 2.09e (Raytest).

Stability of RNAP-DNA and CopR-DNA complexes. Equilibrium mixtures were prepared by incubating $1 \mathrm{nM}$ labelled DNA fragment and varying concentrations of protein (RNAP or CopR) in BB at $37{ }^{\circ} \mathrm{C}$. Dissociation of complexes between labelled DNA and either protein was made irreversible by addition of 50 -fold molar excess of competing unlabelled promoter/operator fragment. Fractions of complexed and free labelled DNA were directly quantified as above. Data were analysed according to the equation for a first-order kinetic process:

$[$ complex $]=[\text { complex }]_{0} \cdot e^{-k \cdot t}$

where [complex] represents the concentration of the complex between either RNAP or CopR and the labelled DNA at time $t$, and [complex $]_{0}$ is its value at $t=0$. The equation was transformed to allow calculation of complex half-lives:

$[\text { complex }]_{t}=[\text { complex }]_{0} \cdot(0.5)^{t / t_{1 / 2}}$

The half-life $\left(t_{1 / 2}\right)$ of the complexes was calculated by fitting the data obtained to the equation using non-linear regression.
DNase I footprinting. The $20 \mu \mathrm{l}$ reaction mixture contained $1 \mathrm{nM}$ of a $235 \mathrm{bp} \gamma_{-}^{32} \mathrm{P}$-labelled DNA fragment obtained by PCR from plasmid pPR1 as template with labelled primer SB6 (5'-CAA CAG AAC CAG AAC CAG AAA- $3^{\prime}$ ) and unlabelled primer SB466 (5' -TTA ATT GAT TGG TGG TAA TC- $\left.3^{\prime}\right), 0.5 \times$ TBE, 0.025 g herring sperm $\mathrm{DNA} \mathrm{l}^{-1}, 6.25 \mathrm{mM} \mathrm{MgCl}_{2}$ and $4.4 \mu \mathrm{M} \mathrm{His}_{6}$-CopR or $90 \mathrm{nM}$ native $B$. subtilis RNAP. Incubation was for $30 \mathrm{~min}$ at $30{ }^{\circ} \mathrm{C}$. Subsequently, DNase I cleavage was initiated by addition of $1 \mu \mathrm{l}(0.05 \mathrm{U})$ of freshly diluted DNase I (Roche) followed by incubation for $2 \mathrm{~min}$ at $37^{\circ} \mathrm{C}$. The reaction was stopped by phenol/chloroform extraction. After ethanol precipitation, the pellet was washed with $80 \%$ ethanol and dissolved in $2 \mu \mathrm{H}_{2} \mathrm{O}$ and $2 \mu \mathrm{l}$ formamide loading dye. Samples were denatured at $75{ }^{\circ} \mathrm{C}$ for $5 \mathrm{~min}$ and separated on a $6 \%$ denaturing PAA gel containing $7 \mathrm{M}$ urea. As size marker, a dideoxy sequencing reaction using plasmid pPR1 and primer SB6 was loaded in parallel. The dried gel was subjected to PhosphorImaging (Fujix BAS 1000).

$\mathbf{K M n O}_{\mathbf{4}}$ footprinting. $\mathrm{KMnO}_{4}$ footprinting was performed according to Sasse-Dwight \& Gralla (1989), with a few modifications. A $20 \mu \mathrm{l}$ reaction mixture contained $1 \mathrm{nM}$ of a $\gamma-{ }^{32} \mathrm{P}$-labelled DNA fragment obtained by PCR from plasmid PPR1 as template with labelled primer SB6 and unlabelled primer SB466, $0.5 \times$ TBE, $0.025 \mathrm{~g}$ herring sperm DNA $1^{-1}, 6.25 \mathrm{mM} \mathrm{MgCl}_{2}$ and $2.2 \mu \mathrm{M}$ or $4.4 \mu \mathrm{M} \mathrm{His}{ }_{6}$-CopR. Subsequently, native $B$. subtilis RNAP was added to $90 \mathrm{nM}$ final concentration, and incubation was for $30 \mathrm{~min}$ at $30^{\circ} \mathrm{C}$. Singlestranded DNA was modified for $2 \mathrm{~min}$ at $37{ }^{\circ} \mathrm{C}$ by addition of $2.5 \mu \mathrm{l}$ $80 \mathrm{mM} \mathrm{KMnO}_{4}$ (freshly prepared from a $0.37 \mathrm{M}$ stock solution). The reaction was stopped with $2 \mu 12.8 \mathrm{M} \beta$-mercaptoethanol; the DNA was precipitated with ethanol, washed with $80 \%$ ethanol and dissolved in $10 \%$ piperidine followed by a $30 \mathrm{~min}$ incubation at $95{ }^{\circ} \mathrm{C}$. The cleavage products were precipitated with ethanol, washed with $80 \%$ ethanol and dissolved in $2 \mu \mathrm{H}_{2} \mathrm{O}$, followed by addition of $2 \mu \mathrm{l}$ formamide loading dye. After denaturation for $5 \mathrm{~min}$ at $75{ }^{\circ} \mathrm{C}$, the samples were separated on a $6 \%$ denaturing PAA gel containing $7 \mathrm{M}$ urea. Visualization and quantification of the bands were performed as for EMSAs.

\section{RESULTS}

\section{RNAP-pll complexes are 18-fold more stable than CopR-operator complexes}

In the case of the rep promoter $\mathrm{P}_{\mathrm{cr}}$ of plasmid pMV158, which replicates in both Gram-positive bacteria and E. coli, a huge difference between the stability of the RNAPpromoter complexes at $37^{\circ} \mathrm{C}$ and at $0{ }^{\circ} \mathrm{C}$ was found (Hernández-Arriaga et al., 2009). Whereas the $37^{\circ} \mathrm{C}$ complex was extremely stable, with a half-life of $\approx 3 \mathrm{~h}$, the $0{ }^{\circ} \mathrm{C}$ complex was very short-lived and no half-life could be determined. To find out whether this is also the case for the complexes of $B$. subtilis RNAP with promoter pII of plasmid pIP501, we performed EMSAs at $4{ }^{\circ} \mathrm{C}$ and $37^{\circ} \mathrm{C}$. However, no differences could be observed. Therefore, all subsequent gel-shift experiments were carried out at $37^{\circ} \mathrm{C}$.

Firstly, the kinetics of dissociation of RNAP- $\mathrm{p}_{\mathrm{II}}$ complexes was investigated. Seven equilibrium mixtures containing $1 \mathrm{nM}$ labelled promoter/operator fragment and $220 \mathrm{nM}$ RNAP were prepared at $37{ }^{\circ} \mathrm{C}$. At different time points, dissociation was initiated by adding a 50 -fold excess of competing unlabelled fragment to the single tubes. Total 
incubation time for RNAP with the labelled fragment was $70 \mathrm{~min}$, so the incubation with the excess unlabelled promoter fragment varied over time. All samples were loaded after the $70 \mathrm{~min}$ time point on a native PAA gel (Fig. 2a). The dissociation of the RNAP-pII complexes appeared to follow first-order kinetics, which yielded a dissociation rate constant $k_{\mathrm{d}}$ of $5.25 \times 10^{-4} \mathrm{~s}^{-1}$, corresponding to a half-life of $\approx 22 \mathrm{~min}$. Experiments with different RNAP concentrations resulted in the same halflife (not shown).

Secondly, the kinetics of dissociation of CopR-operator complexes was measured as above at $37{ }^{\circ} \mathrm{C}$, employing a 50 -fold excess of competing unlabelled DNA (Fig. 2b). The equilibrium mixtures contained $1.2 \mu \mathrm{M}$ CopR and $1 \mathrm{nM}$ labelled promoter/operator fragment. Dissociation was initiated by adding unlabelled competitor. Total incubation time was $25 \mathrm{~min}$. The experiment was performed twice with different CopR concentrations $(1.2 \mu \mathrm{M}$ and $2.4 \mu \mathrm{M})$. Both yielded similar dissociation rate constants of $9.6 \times 10^{-3} \mathrm{~s}^{-1}$ (Fig. 2b), which corresponded to a half-life of $\approx 72 \mathrm{~s}$.

From our data we can conclude that the stability of CopRpII complexes is 18 -fold lower than that of RNAP-pII complexes.

\section{The binding sites of CopR and RNAP at the repR promoter pll overlap}

DNase I footprinting was used to investigate the binding of RNAP and CopR at the promoter/operator region of pII. To this end, a 235 bp labelled DNA fragment was incubated with either $B$. subtilis RNA polymerase (90 $\mathrm{nM})$ or $\mathrm{His}_{6}$-CopR $(4.4 \mu \mathrm{M})$, or simultaneously with both proteins, and the complexes were subsequently treated with DNase I. As shown in Fig. 3, the RNA polymerase protected the region between -58 and +15 $(+1$ is the transcription start site). This region includes the binding site for the $\alpha$ CTD between -40 and -60 . Here, additionally, strong enhancements of DNase I reactivity on the opposite side of the double helix, probably originating from distortion of the upstream region as a result of an $\alpha \mathrm{CTD}$ interaction, are seen. The region protected by RNAP clearly overlaps the CopR binding site between -62 and -37 . Although the minimal recognition region of CopR comprises $17 \mathrm{bp}$, earlier ethylation and methylation interference footprinting had shown that up to five more nucleotides are contacted - albeit weakly upstream and downstream of these 17 bp (Steinmetzer \& Brantl, 1997). This was confirmed later by hydroxyl radical footprinting studies (Steinmetzer et al., 2002a), where a $29 \mathrm{bp}$ region was protected and contacts were found (a)

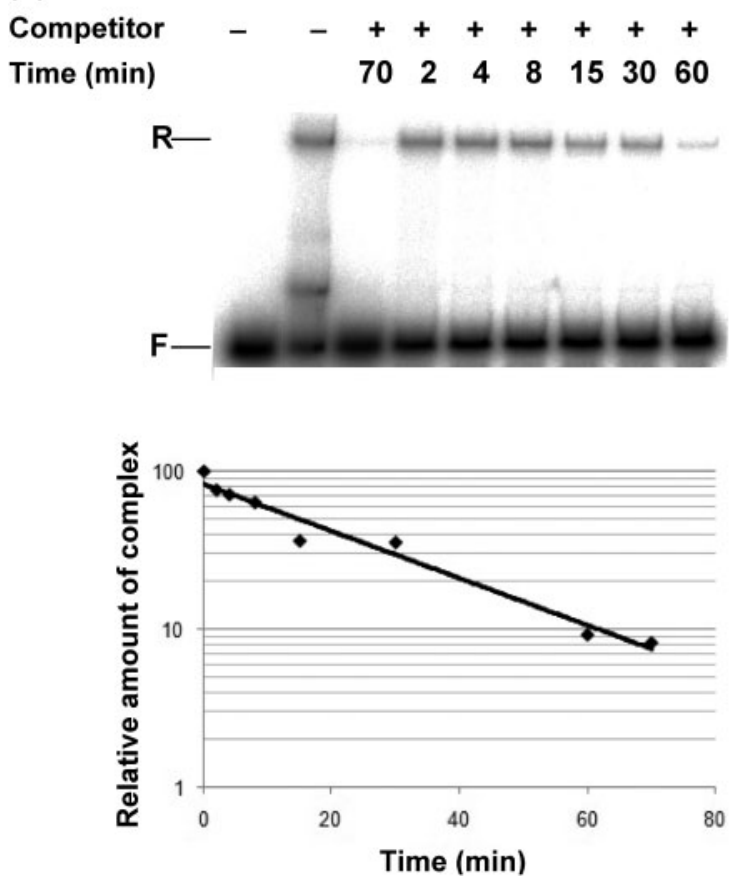

(b)

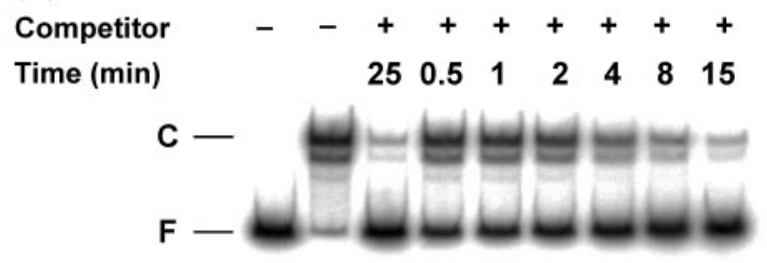

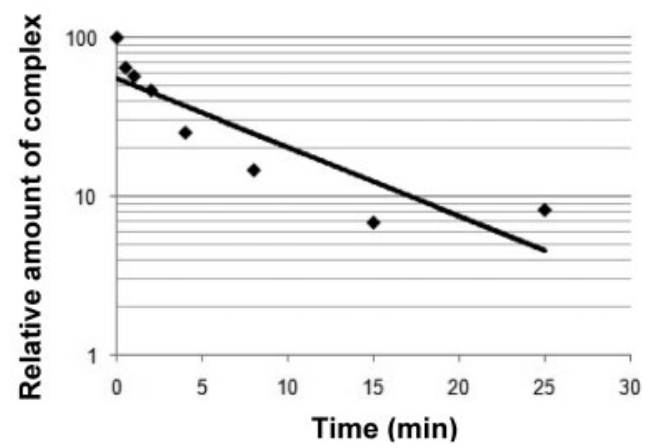

Fig. 2. Kinetics of dissociation of RNAP-II and CopR-pll complexes at $37{ }^{\circ} \mathrm{C}$. (a) EMSA analysis of the stability of the RNAPpll complexes. Equilibrium mixtures contained $220 \mathrm{nM} \mathrm{His}{ }_{6}$-RNAP and $1 \mathrm{nM}$ labelled DNA. The total incubation time was $70 \mathrm{~min}$, but at the indicated time points, a 50-fold excess of unlabelled DNA was added. Analysis was on a $5 \%$ native PAA gel. (b) EMSA analysis of the stability of the CopR-operator/pll complex. Conditions were as in (a), except that $1.2 \mu \mathrm{M}$ CopR was used and total incubation time was 25 min. R, RNAP-DNA complex; C, CopR-DNA complex; F, free target DNA. Below the autoradiographs of the gels in (a) and (b) linear fits of the corresponding data are shown. 
between positions -60 and -36 on the top strand and between positions -65 and -40 on the bottom strand. Three distinct areas of protection - I, II and III - visible on the top and on the bottom strand are marked by grey lines in Fig. 3. The footprint pattern of the bottom strand was shifted by $4-5 \mathrm{nt}$ in the $3^{\prime}$ direction compared with the top strand. The additional footprint III compared with the data from chemical interference footprinting (Steinmetzer \& Brantl, 1997) resulted from non-base-specific contacts between CopR and DNA (Steinmetzer et al., 2002a). The DNase I footprinting data presented here corroborate the previous finding that CopR interacts with a few more nucleotides upstream and downstream of its minimal binding region. Therefore, we can deduce that the binding region of CopR overlaps partially with the binding region of RNAP (see Fig. 3). The concurrent addition of both proteins yields a mixture of both single footprints. No modified bands indicative of simultaneous binding of CopR and RNAP are visible.

From the footprinting data one would expect a competition between RNAP binding and CopR binding. However, DNase I footprinting does not allow us to determine unequivocally whether CopR and RNAP can bind at the same time. To answer this question, we resorted to EMSAs.

\section{CopR and RNAP compete for binding to the target DNA}

In EMSAs performed by addition of both CopR and RNAP at the same time or consecutively, no supershifted bands could be detected (e.g. Fig. 4), demonstrating that binding of these molecules at pII is mutually exclusive. This result is in agreement with the overlapping binding regions of the two proteins. To investigate whether CopR and RNAP can dislodge each other at promoter pII, a time-dependent EMSA analysis was applied (Fig. 4). Recent calculations from E. coli showed that in both exponential and stationary phase, on average $\approx 2600$ molecules of RNAP are present in one bacterial cell (Piper et al., 2009). These are either engaged in ongoing transcription or bound to low-affinity sites, i.e. only a few free molecules are available. For wildtype B. subtilis strain DB104 containing low-copy-number pIP501 deriviative pCOP4, the number of CopR monomers per cell was calculated to be $\approx 15000$, corresponding to an intracellular CopR concentration of roughly 20$30 \mu \mathrm{M}$ (Steinmetzer et al., 1998). To simulate the in vivo situation where CopR is in large excess over free RNAP, and to be still able to detect protein-DNA complexes, we used $4.7 \mu \mathrm{M}$ CopR and $0.22 \mu \mathrm{M}$ RNAP. First, the timedependent displacement of RNAP by CopR was analysed. To this end, RNAP and a labelled $210 \mathrm{bp}$ promoter/ operator fragment were incubated at $37{ }^{\circ} \mathrm{C}$, and CopR was added at different time points. Total incubation time was 70 min. As shown in Fig. 4(a), already after $0.5 \mathrm{~min}$, a strong CopR-DNA complex was visible, and after $70 \mathrm{~min}$, only a weak RNAP-DNA complex could be detected, comprising $\approx 20 \%$ of the initially bound RNAP.

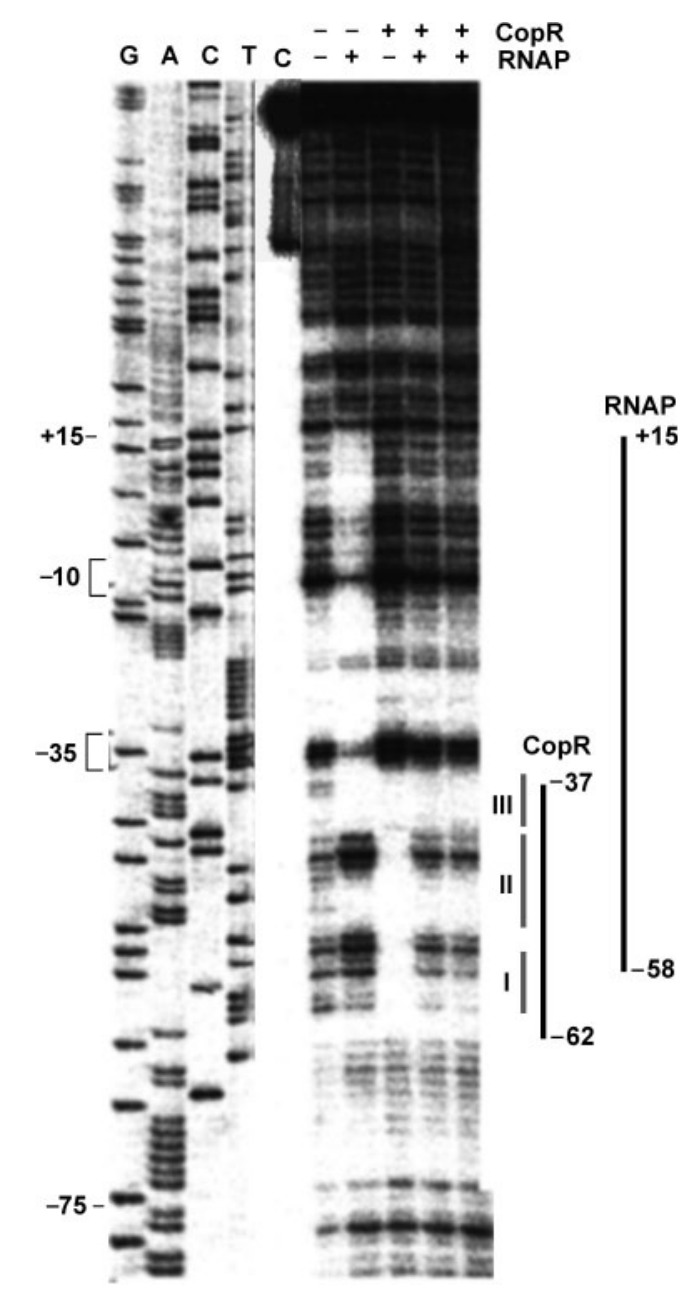

Fig. 3. The binding sites of CopR and RNAP overlap partially. DNase I footprinting analyses of the interaction of CopR and RNAP with promoter pll were performed as described in Methods. On the left margin, nt positions around pll are shown. The regions protected by CopR and RNAP are indicated by thick black lines. Grey lines indicate the protected regions I to III from previous hydroxyl radical footprinting assays (Steinmetzer et al., 2002b). C, control without DNase and without proteins. Left panel, Sanger sequencing reaction on plasmid pPR1 with primer SB6. CopR was added to a final concentration of $4.4 \mu \mathrm{M}$, RNAP to $90 \mathrm{nM}$. In the last two lanes, $4.4 \mu \mathrm{M}$ CopR and RNAP (90 or $180 \mathrm{nM}$ ) were applied simultaneously.

The time-dependent displacement of CopR by RNAP was analysed in the same way, but here, CopR was added first, and RNAP was added after the same time points (Fig. 4b). Although virtually all operator sites were already saturated with CopR after $0.5 \mathrm{~min}$, a faint RNAP-DNA complex appeared, which became stronger with increasing incubation time. Apparently, the rapid dissociation of the CopRoperator complexes compared to the 18 -fold more stable RNAP-DNA complexes accounts for the displacement of the repressor by the polymerase: the addition of RNAP to a previously equilibrated CopR-DNA binding mixture 
(a)
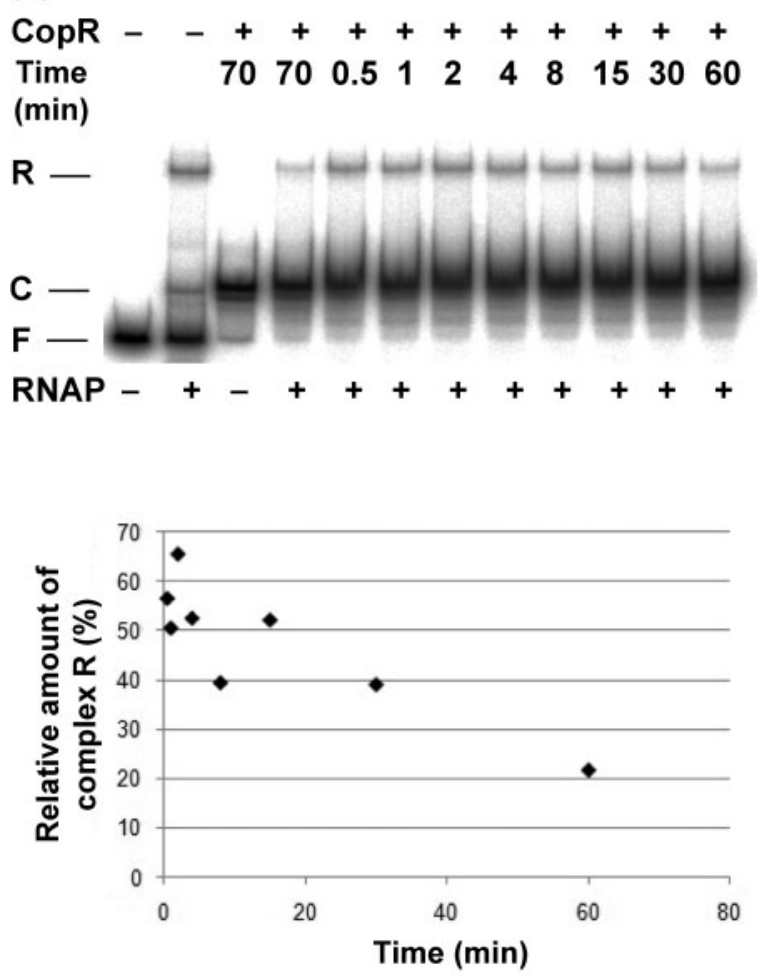

(b)
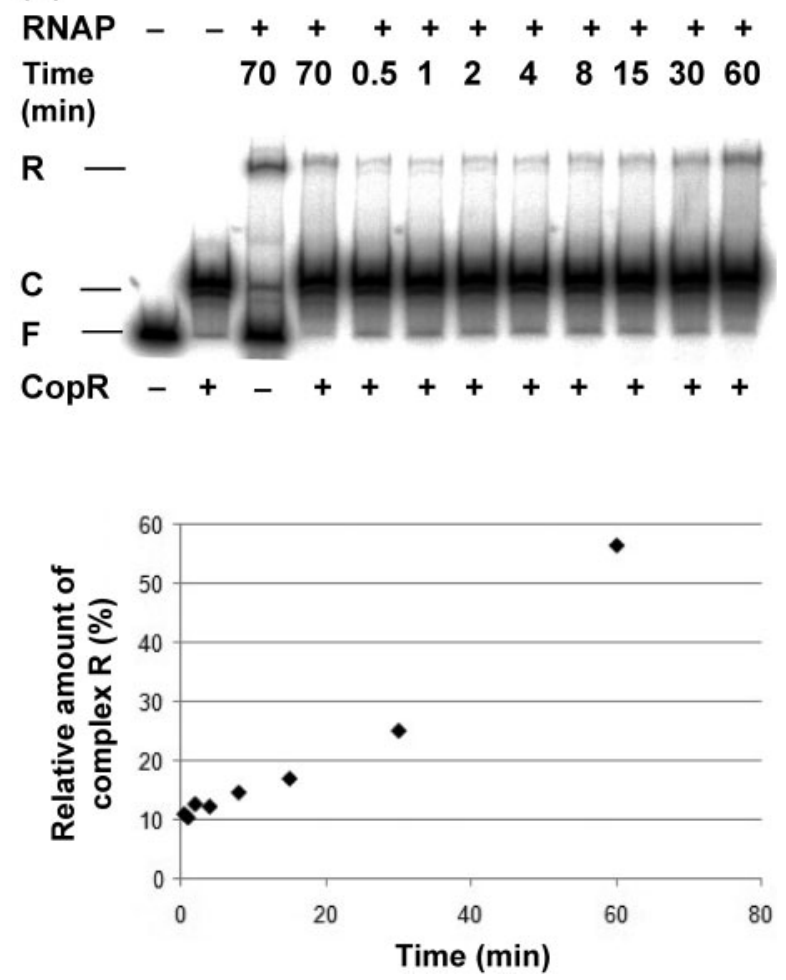

Fig. 4. CopR and RNAP compete for binding at promoter pll. (a) Time-dependent displacement of RNAP by CopR. RNAP $(220 \mathrm{nM})$ was mixed with labelled DNA in binding buffer, and, at different time points, CopR was added to $4.7 \mu \mathrm{M}$. Total incubation was for $70 \mathrm{~min}$ at $37{ }^{\circ} \mathrm{C}$, followed by separation on a $5 \%$ native PAA gel. (b) Time-dependent displacement of CopR by RNAP. CopR $(4.7 \mu \mathrm{M})$ was mixed with labelled DNA in binding buffer, and, at different time points, RNAP was added to $220 \mathrm{nM}$. Incubation and separation were as in (a). R, RNAP-DNA complex; C, CopR-DNA complex; F, free target DNA. The incubation times with the corresponding competitor are indicated above the gels.

passively displaces the equilibrium in the direction of the dissociation of the CopR-DNA complexes, by sequestering free DNA. Although - after 70 min incubation - CopR bound $98.8 \%$ of the labelled DNA fragment whereas RNAP bound only $1.2 \%$, our data show that CopR and RNAP can displace each other at the repR promoter pII, i.e. they can compete for binding.

\section{CopR inhibits RNAP binding at promoter pll}

To investigate whether CopR acts by steric hindrance, i.e. prevention of binding of the RNAP at promoter pII, we studied the concentration-dependent displacement of RNAP by CopR using EMSAs. First, a labelled pII/operator DNA fragment was incubated with different concentrations of CopR in the absence of RNAP (Fig. 5a). At $4.7 \mu \mathrm{M}$ CopR, all DNA was bound by CopR, and at $19 \mu \mathrm{M}$, both specific and unspecific CopR-DNA complexes could be observed. Such complexes were detected previously (Steinmetzer et al., 1998) and most probably also exist in vivo at the 20-30 $\mu \mathrm{M}$ intracellular CopR concentration. In the second experiment, $0.22 \mu \mathrm{M}$ RNAP was mixed with different concentrations of CopR and competition was started by adding the reaction mixture containing the labelled target DNA (Fig. 5b) followed by $30 \mathrm{~min}$ incubation at $37^{\circ} \mathrm{C}$. Already at $0.3 \mu \mathrm{M}$ CopR, a clear displacement of RNAP could be observed, but even at $19 \mu \mathrm{M}$ CopR, about $20 \%$ of the DNA molecules originally bound by RNAP were still present in complex with pII. The competition experiment was repeated with two other RNAP concentrations $(0.44 \mu \mathrm{M}$ and $0.88 \mu \mathrm{M})$, but the results were the same. Therefore, we can conclude that CopR inhibits in vitro binding of the RNAP to promoter pII approximately fivefold.

\section{CopR obstructs open complex formation at promoter pll}

The EMSAs revealed that even at high concentrations of CopR the formation of the RNAP-pII complex is not completely inhibited (Fig. 5). For pMV158-encoded CopG two functions were found: it prevents access of RNAP to the promoter and it actively dissociates open complexes (Hernández-Arriaga et al., 2009). To investigate whether as well as inhibiting RNAP binding, CopR also dissociates open complexes, we studied the effect of CopR on the 
(a)

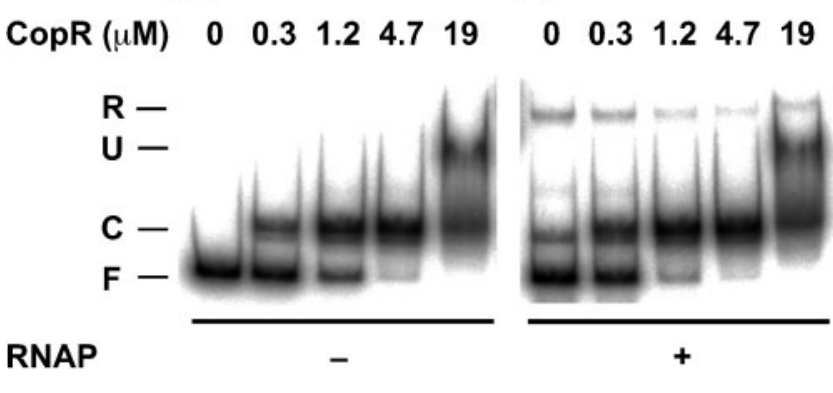

Fig. 5. CopR inhibits binding of RNAP to promoter pll. (a) EMSA analysis of CopR binding to its operator. Increasing amounts of CopR were added to labelled DNA ( $1 \mathrm{nM})$ and incubation was for $30 \mathrm{~min}$ at $37{ }^{\circ} \mathrm{C}$, followed by separation on a $5 \%$ native PAA gel. (b) EMSA analysis of concentration-dependent displacement of RNAP by CopR. RNAP (220 nM) was mixed with increasing amounts of CopR, and subsequently a reaction mix containing binding buffer and $1 \mathrm{nM}$ labelled DNA was added. Incubation and gel separation were as in (a). R, RNAP-DNA complex; U, unspecific CopR-DNA complex; C, CopR-DNA complex; F, free DNA target.

formation of open RNAP-pII complexes by $\mathrm{KMnO}_{4}$ footprinting. $\mathrm{KMnO}_{4}$ preferentially oxidizes the 5,6 double bond of pyrimidine bases in distorted or denatured regions of DNA or at their junction with native duplex DNA. Therefore, it has been used to examine the extent of the melted region of an open RNAP-promoter complex (Sasse-Dwight \& Gralla, 1989). A labelled 235 bp DNA fragment containing the CopR operator and promoter pII was incubated with $B$. subtilis RNAP $(90 \mathrm{nM})$ and $\mathrm{His}_{6}$ CopR $(2.2 \mu \mathrm{M}$ or $4.4 \mu \mathrm{M})$ and subjected to $\mathrm{KMnO}_{4}$ treatment as described in Methods (see Fig. 6). In the absence of CopR, the DNA region between positions -12 and $-3(+1$ is transcription start point) at promoter $\mathrm{pII}$ is partially melted by formation of an open transcription initiation complex. A cleavage of the DNA occurred at thymidines at positions $-12,-10,-7$ and -3 . In the presence of $4.4 \mu \mathrm{M}$ CopR, the formation of this singlestranded region was inhibited by $84 \%$. This result demonstrates that CopR impedes the formation of an open RNAP-promoter complex. However, since CopR already inhibits an earlier step, namely access of RNAP to promoter $\mathrm{pII}$, and this inhibition was calculated to be about $80 \%$, no significant extra contribution of the obstruction of open complex formation was found. Hence, in contrast to CopG, no second activity of CopR could be established.

\section{DISCUSSION}

In this study, we investigated the complexes formed by the $B$. subtilis RNAP at the repR promoter pII and elucidated the mechanism by which CopR represses transcription from this promoter.

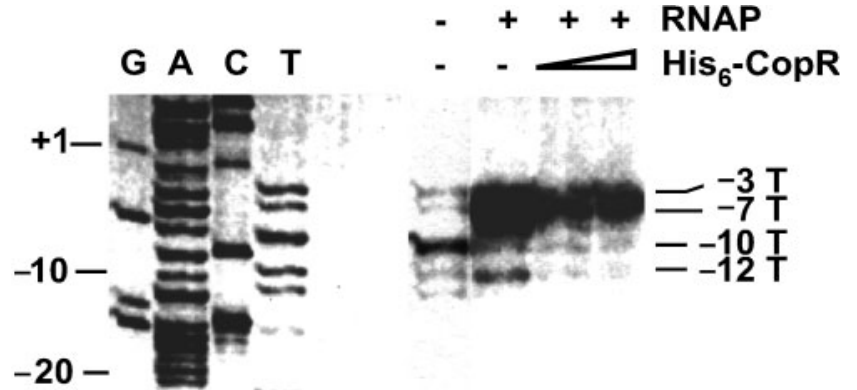

Fig. 6. CopR obstructs open complex formation at promoter pll. $\mathrm{KMnO}_{4}$ footprinting was performed as described in Methods, using $90 \mathrm{nM} \mathrm{B}$. subtilis RNA polymerase and 2.2 or $4.4 \mu \mathrm{M} \mathrm{His}_{6}{ }^{-}$ CopR. The left panel displays a sequencing reaction on plasmid pPR1 with primer SB6. On the left margin, nt positions around pll are shown. The detected single-stranded positions in the open complex are indicated on the right.

Evidence for the repression mechanism used by CopR was provided by competition assays in which the order of addition of RNAP and repressor was inverted. No specific ternary complexes were observed in any case (Figs 4 and 5), demonstrating the mutually exclusive binding of CopR and RNAP to the promoter/operator region. In the presence of both proteins, the apparent equilibrium extent of formation of RNAP-pII complexes depended on the concentration of both proteins (Fig. 5 and unpublished data). Since the intracellular concentration of CopR is much higher than that of freely available RNAP, CopR can successfully compete with RNAP for binding to the same region of the DNA, where promoter and operator overlap (Fig. 3). CopR hinders the access of RNAP to the promoter region by steric exclusion, probably by competing with the $\alpha$ CTD of the polymerase. This constitutes a classical model of action of a transcriptional repressor, which also applies to e.g. $\lambda \mathrm{cI}$ repressor binding to the $\mathrm{O}_{\mathrm{R} 1}$ operator of the $\mathrm{p}_{\mathrm{R}}$ promoter (Hawley et al., 1985), the LexA repressor at the uvrA promoter (Bertrand-Burggraf et al., 1987), the Fur repressor of E. coli (Escolar et al., 1998) and the MalR repressor of S. pneumoniae (Nieto et al., 2001). Although in these conventional cases, steric hindrance occurs by binding of a repressor to sequences that overlap those recognized by RNAP, binding of the polymerase can also be inhibited by proteins like CytR or DnaA whose binding sites do not overlap that of RNAP: E. coli CytR repressor binds at the deo promoter at position -70 (ValentinHansen et al., 1996) and for DnaA, a nucleation site allows binding of additional repressor molecules finally leading to a nucleoprotein complex that impedes RNAP binding (Lee \& Hwang, 1997). 
For CopG of plasmid pMV158 and E. coli RNAP also a partial overlap of the contacted regions has been found, and a simultaneous binding of CopG and RNAP was excluded (Hernández-Arriaga et al., 2009). Furthermore, these authors could show that different sides of the promoter/ operator region were contacted. In the case of CopR, at least in the upper strand, the CopR and RNAP binding sites are located on the same face of the DNA (Fig. 3).

The degree of inhibition by CopR determined in EMSAs and in $\mathrm{KMnO}_{4}$ footprinting was, at $80 \%$ and $84 \%$, nearly the same. Consequently, an additional contribution of the obstruction of open complex formation to the repression mechanism is unlikely. Therefore, a second activity of CopR can be excluded. This is in contrast to what has been found for CopG of plasmid pMV158 and for IclR, an E. coli repressor of the aceBAK operon, where in addition to steric hindrance, the repressors were able to actively dissociate open complexes (Hernández-Arriaga et al., 2009; Yamamoto \& Ishihama, 2003). In the case of IclR, however, this second activity was achieved by binding to a region far upstream of the primary binding site, whereas binding of four CopG molecules to its single operator was responsible for its dual repression mechanism.

Furthermore, we determined that the stability of the CopR-pII complexes $\left(t_{1 / 2} \approx 1.2 \mathrm{~min}\right)$ is 18 -fold lower than that of the RNAP-pII complexes $\left(\mathrm{t}_{1 / 2} \approx 22 \mathrm{~min}\right)$. This is 8 fold less than the determined 771-fold stability difference (Hernández-Arriaga et al., 2009) between the RNAP-P $\mathrm{cr}$ $\left(\mathrm{t}_{1 / 2} \approx 180 \mathrm{~min}\right)$ and the CopG- $\mathrm{P}_{\mathrm{cr}}$ complexes $(14 \mathrm{~s})$. The half-life of the CopR- and CopG-operator complexes was 5 -fold different, but still in the same range. Due to the different sources of RNAP (B. subtilis RNAP for pII and E. coli RNAP for $\mathrm{P}_{\mathrm{cr}}$ ) a direct comparison of the stability of the RNAP-promoter complexes is not feasible. However, the much shorter half-life of the Cop-DNA complexes could explain how in both cases, the repressor can be displaced by the RNAP from its operator. The half-lives of the complexes provide the time frame within which regulation can occur. Since CopR is synthesized constitutively, repression can be achieved quickly, although the half-life of the RNAP-pII complex is quite long. However, when cells divide and the CopR concentration decreases, transcription of the repR mRNA can - due to the short half-life of the CopR-DNA complexes - be resumed immediately.

The fact that even at very high concentrations of CopR, no complete inhibition of RNAP binding was observed (Fig. $5 b)$ is in accordance with the data from previous transcriptional pII-lacZ fusions, where at the enormous concentration of $300 \mu \mathrm{M}$ CopR provided by the multicopy plasmid pCOP9, only a 10 - to 15 -fold decrease in $\beta$ galactosidase activity was measured, but no complete repression of repR mRNA transcription was observed (Brantl, 1994). Two earlier hypotheses for the lack of complete shut-off of repR transcription could be refuted: (i) insufficient levels of CopR from its native promoter were excluded by determining the intracellular CopR concentration to be $20-30 \mu \mathrm{M}$ and (ii) a low binding constant for CopR was ruled out by calculating the $k_{\mathrm{d}}$ of the CopR-operator complex to be $0.4 \mathrm{nM}$ (Steinmetzer et al., 1998). We suggest that the displacement of CopR by RNAP observed here is responsible for the inability of CopR to totally repress pII. This result accords with the previous observation that the $\mathrm{P}_{\text {cr }}$ promoter of plasmid pMV158 is also never totally blocked by CopG (del Solar et al., 1990), which forms an even 771-fold less stable complex with its target than RNAP (Hernández-Arriaga et al., 2009). By contrast, a third plasmid-encoded Cop repressor, CopB from E. coli plasmid R1, can totally silence its cognate repA promoter, which is activated only when the plasmid copy number drops dramatically (Nordström et al., 1984). However, for CopB/RNAP and the repA promoter, no reciprocal displacement studies have been conducted.

The CopR protein of streptococcal plasmid pIP501 is highly homologous to the Cop proteins of the related plasmids pSM19035 (CopS, Ceglowski et al., 1993) and pAM $\beta 1$ (CopF, Swinfield et al., 1990). Their amino acid sequences diverge only at the $\mathrm{C}$ terminus, which is solely responsible for protein stability (Kuhn et al., 2000, 2001). Furthermore, the three Cop operator sites are almost identical, differing only in the spacer region between binding sites I and II and in the flanking region. Our previous SELEX experiments showed that these minor differences are negligible as regards efficient binding and regulation in vivo (Freede \& Brantl, 2004). Therefore, we conclude that all three Cop repressors use the same classic mechanism - steric hindrance - to exert their inhibitory effects.

\section{ACKNOWLEDGEMENTS}

We thank Margarita Salas, Madrid, Spain, for kindly providing us with purified native B. subtilis RNA polymerase, and Anne Galinier (Marseille, France), for sending us a strain for the purification of His $_{6}$-tagged B. subtilis RNA polymerase. This work was supported by grants to S.B. from the Deutsche Forschungsgemeinschaft (nos BR1552/4-2 and BR1552/6-2).

\section{REFERENCES}

Bertrand-Burggraf, E., Hurstel, S., Daune, M. \& Schnarr, M. (1987). Promoter properties and negative regulation of the uvrA gene by the LexA repressor and its amino-terminal DNA binding domain. $J \mathrm{Mol}$ Biol 193, 293-302.

Brantl, S. (1994). The $\operatorname{cop} R$ gene product of plasmid pIP501 acts as a transcriptional repressor at the essential repR promoter. Mol Microbiol 14, 473-483.

Brantl, S. \& Behnke, D. (1992). Copy number control of the streptococcal plasmid pIP501 occurs at three levels. Nucleic Acids Res 20, 395-400.

Brantl, S. \& Wagner, E. G. H. (1994). Antisense RNA-mediated transcriptional attenuation occurs faster than stable antisense/target RNA pairing: an in vitro study of plasmid pIP501. EMBO J 13, 35993607. 
Brantl, S. \& Wagner, E. G. H. (1997). Dual function of the $\operatorname{cop} R$ gene product of plasmid pIP501. J Bacteriol 179, 7016-7024.

Brantl, S., Behnke, D. \& Alonso, J. C. (1990). Molecular analysis of the replication region of the conjugative Streptococcus agalactiae plasmid pIP501 in Bacillus subtilis. Comparison with plasmids pAM $\beta$ 1 and pSM19035. Nucleic Acids Res 18, 4783-4790.

Brantl, S., Birch-Hirschfeld, E. \& Behnke, D. (1993). RepR protein expression on plasmid pIP501 is controlled by an antisense RNAmediated transcription attenuation mechanism. J Bacteriol 175, 40524061.

Ceglowski, P., Lurz, R. \& Alonso, J. C. (1993). Functional analysis of pSM19035-derived replicons in Bacillus subtilis. FEMS Microbiol Lett 109, 145-150.

del Solar, G. H., Pérez-Martín, J. \& Espinosa, M. (1990). Plasmid pLS1-encoded RepA protein regulates transcription from repAB promoter by binding to a DNA sequence containing a 13-base pair symmetric element. J Biol Chem 265, 12569-12575.

Escolar, L., Pérez-Martín, J. \& de Lorenzo, V. (1998). Coordinated repression in vitro of the divergent fepA-fes promoters of Escherichia coli by the iron uptake regulation (Fur) protein. J Bacteriol 180, 2579-2582.

Freede, P. \& Brantl, S. (2004). Transcriptional repressor CopR: use of SELEX to study the $\operatorname{cop} R$ operator indicates that evolution was directed at maximal binding affinity. J Bacteriol 186, 6254-6264.

Greene, E. A. \& Spiegelman, G. B. (1996). The Spo0A protein of Bacillus subtilis inhibits transcription of the $a b r B$ gene without preventing binding of the polymerase to the promoter. J Biol Chem 271, 11455-11461.

Hawley, D. K., Johnson, A. D. \& McClure, W. R. (1985). Functional and physical characterization of transcription initiation complexes in the bacteriophage $\lambda \mathrm{O}_{\mathrm{R}}$ region. J Biol Chem 260, 8618-8626.

Hernández-Arriaga, A. M., Rubio-Lepe, T. S., Espinosa, M. \& del Solar, G. (2009). Repressor CopG prevents access of RNA polymerase to promoter and actively dissociates open complexes. Nucleic Acids Res 37, 4799-4811.

Kuhn, K., Steinmetzer, K. \& Brantl, S. (2000). Transcriptional repressor CopR: the structured acidic C terminus is important for protein stability. J Mol Biol 300, 1021-1031.

Kuhn, K., Steinmetzer, K. \& Brantl, S. (2001). Transcriptional repressor CopR: dissection of stabilizing motifs within the $\mathrm{C}$ terminus. Microbiology 147, 3387-3392.

Lee, Y. S. \& Hwang, D. S. (1997). Occlusion of RNA polymerase by oligomerization of DnaA protein over the $d n a A$ promoter of Escherichia coli. J Biol Chem 272, 83-88.

Licht, A. \& Brantl, S. (2009). The transcriptional repressor CcpN from Bacillus subtilis uses different repression mechanisms at different promoters. J Biol Chem 284, 30032-30038.

Monsalve, M., Mencia, M., Salas, M. \& Rojo, F. (1996). Protein p4 represses phage $\Phi 29$ A2c promoter by interacting with the $\alpha$ subunit of Bacillus subtilis RNA polymerase. Proc Natl Acad Sci U S A 93, 8913-8918.

Nieto, C., Puyet, A. \& Espinosa, M. (2001). MalR-mediated regulation of the Streptococcus pneumoniae malMP operon at promoter $\mathrm{P}_{\mathrm{M}}$. Influence of a proximal divergent promoter region and competition between MalR and RNA polymerase proteins. J Biol Chem 276, 14946-14954.

Nordström, K., Molin, S. \& Light, J. (1984). Control of replication of bacterial plasmids: genetics, molecular biology, and physiology of the plasmid R1 system. Plasmid 12, 71-90.

Piper, S. E., Mitchell, J. E., Lee, D. J. \& Busby, S. J. (2009). A global view of Escherichia coli Rsd protein and its interactions. Mol Biosyst 5, 1943-1947.

Rojo, F. (1999). Repression of transcription initiation in bacteria. J Bacteriol 181, 2987-2991.

Rojo, F. (2001). Mechanisms of transcriptional repression. Curr Opin Microbiol 4, 145-151.

Sasse-Dwight, S. \& Gralla, J. D. (1989). $\mathrm{KMnO}_{4}$ as a probe for lac promoter DNA melting and mechanism in vivo. J Biol Chem 264, 8074-8081.

Schneider, R., Travers, A., Kutateladze, T. \& Muskhelishvili, G. (1999). A DNA architectural protein couples cellular physiology and DNA topology in Escherichia coli. Mol Microbiol 34, 953-964.

Smith, T. L. \& Sauer, R. T. (1996). Role of operator subsites in Arc repression. J Mol Biol 264, 233-242.

Steinmetzer, K. \& Brantl, S. (1997). Plasmid pIP501 encoded transcriptional repressor CopR binds asymmetrically at two consecutive major grooves of the DNA. J Mol Biol 269, 684-693.

Steinmetzer, K., Behlke, J. \& Brantl, S. (1998). Plasmid pIP501 encoded transcriptional repressor CopR binds to its target DNA as a dimer. J Mol Biol 283, 595-603.

Steinmetzer, K., Hillisch, A., Behlke, J. \& Brantl, S. (2000a). Transcriptional repressor CopR: structure model-based localization of the deoxyribonucleic acid binding motif. Proteins 38, 393-406.

Steinmetzer, K., Hillisch, A., Behlke, J. \& Brantl, S. (2000b). Transcriptional repressor CopR: amino acids involved in forming the dimeric interface. Proteins 39, 408-416.

Steinmetzer, K., Kuhn, K., Behlke, J., Golbik, R. \& Brantl, S. (2002a). Plasmid pIP501 encoded transcriptional repressor CopR: single amino acids involved in dimerization are also important for folding of the monomer. Plasmid 47, 201-209.

Steinmetzer, K., Behlke, J., Brantl, S. \& Lorenz, M. (2002b). CopR binds and bends its target DNA: a footprinting and fluorescence resonance energy transfer study. Nucleic Acids Res 30, 2052-2060.

Swinfield, T. J., Oultram, J. D., Thompson, D. E., Brehm, J. K. \& Minton, N. P. (1990). Physical characterisation of the replication region of the Streptococcus faecalis plasmid pAM $\beta$ 1. Gene 87, 79-90.

Valentin-Hansen, P., Søgaard-Andersen, L. \& Pedersen, H. (1996). A flexible partnership: the CytR anti-activator and the cAMP-CRP activator protein, comrades in transcription control. Mol Microbiol 20, 461-466.

Yamamoto, K. \& Ishihama, A. (2003). Two different modes of transcription repression of the Escherichia coli acetate operon by IclR. Mol Microbiol 47, 183-194.

Edited by: K. E. Weaver 